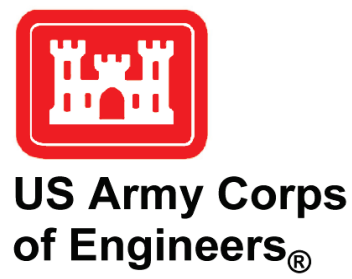

\title{
Three Dimensional Shallow Water Adaptive Hydraulics (ADH-SW3): Waterborne Vessels
}

by Gaurav Savant and Corey J. Trahan

PURPOSE: This Coastal and Hydraulics Engineering Technical Note (CHETN) describes the implementation and testing of waterborne vessels induced pressure and stresses into the threedimensional (3D) shallow water module (SW) of the Adaptive Hydraulics (AdH) numerical code. A description of the inputs required by the user is also provided and serves as the user's guide.

BACKGROUND: The movement of a vessel through a water body produces currents and waves. Maynord (1996) provided a general description of these waves and currents and provided analytical tools to describe the effects of these currents on the hydrodynamics of the water body. Stockstill et al. (1999) showed that by applying the pressure imposed on the water surface by the vessel into a numerical model, these currents and their far-field effects can be accurately simulated. In this technical note the authors expand the two-dimensional (2D) shallow water implementation presented by Stockstill et al. (1999) into the 3D shallow water realm.

A variety of 3D reservoir, riverine, coastal, and estuarine simulation models exist (such as ADHSW3, CH3D, TABS-MDS, etc.). These models solve some form of the Reynolds averaged NavierStokes equations using the hydrostatic assumption. The governing equations for velocity $(u, v, w)$ are written as

$$
\begin{gathered}
\frac{\partial u}{\partial x}+\frac{\partial v}{\partial y}+\frac{\partial w}{\partial z}=0 \\
\frac{\partial u}{\partial t}+\frac{\partial u u}{\partial x}+\frac{\partial v u}{\partial y}+\frac{\partial w u}{\partial z}-\frac{1}{\rho_{0}}\left(\frac{\partial P}{\partial x}\right)-\frac{1}{\rho_{0}}\left(\frac{\partial E_{x x} \frac{\partial u}{\partial x}}{\partial x}+\frac{\partial E_{x y} \frac{\partial u}{\partial y}}{\partial y}+\frac{\partial E_{x z} \frac{\partial u}{\partial z}}{\partial z}\right)=0 \\
\frac{\partial v}{\partial t}+\frac{\partial u v}{\partial x}+\frac{\partial v v}{\partial y}+\frac{\partial w v}{\partial z}-\frac{1}{\rho_{0}}\left(\frac{\partial P}{\partial y}\right)-\frac{1}{\rho_{0}}\left(\frac{\partial E_{y x} \frac{\partial v}{\partial x}}{\partial x}+\frac{\partial E_{y y} \frac{\partial v}{\partial y}}{\partial y}+\frac{\partial E_{y z} \frac{\partial v}{\partial z}}{\partial z}\right)=0
\end{gathered}
$$

where, $E_{x x}, E_{x y}, E_{y x}, E_{x z}, E_{y y}$, and $E_{y z}$ are kinematic eddy viscosities (subscripts indicates directionality), $\rho_{0}$ is the reference density, and $P$ is the hydrostatic pressure. The horizontal $\left(E_{x x}, E_{y y}, E_{x y}, E_{y x}\right)$ and vertical $\left(E_{x z}, E_{y z}\right)$ eddy viscosity for momentum coefficients are utilized to represent the Reynolds stresses and are obtained through turbulence closure schemes. 
Under the hydrostatic pressure assumption, vertical accelerations are neglected, and the equation for $w$ yields the following equation for the pressure term:

$$
P(z)=P_{a}+\int_{z}^{\eta} g \rho(z) d z
$$

where $P_{a}$ is the atmospheric pressure, $g$ is the acceleration due to gravity, $\rho(z)$ is the density at a location in the $z$ direction, and $\eta$ is the water surface elevation.

INCLUSION OF VESSEL PRESSURE FIELD: In ADH-SW3, the pressure applied $(P(\mathrm{z}))$ is a function of the atmospheric pressure $\left(P_{a}\right)$, usually assumed to be zero in the absence of an atmospheric pressure field, and the location of the node under consideration in the $z$ direction. This hydrostatic pressure component $\left(\int_{z}^{\eta} g \rho(z) d z\right.$ ) is internally normalized by the product of gravity and density so that the resulting pressure is in terms of the depth of the node under consideration.

Incorporation of boat pressures into ADH-SW3 takes advantage of this, and the atmospheric pressure $\left(P_{a}\right)$ is incremented by a value equal to the draft of the vessel directly over the node under consideration. This results in Equation 4 being modified as follows:

$$
P(z)=P_{a}+P_{b}+\int_{z}^{\eta} g \rho(z) d z
$$

Where $P_{b}$ is the vessel imposed draft or pressure, and other variables are the same as defined previously.

Figure 1 illustrates this vessel-imposed pressure.

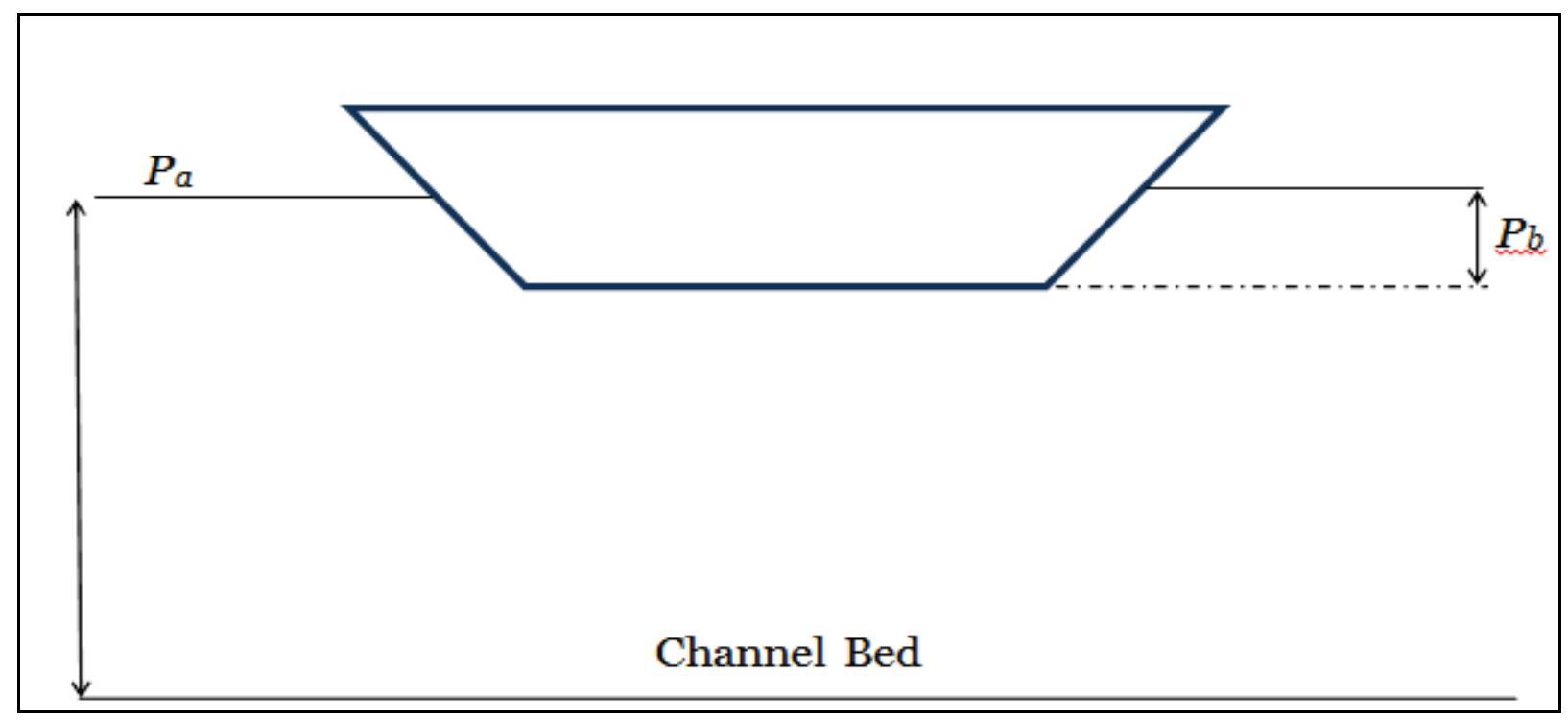

Figure 1. Vessel pressure. 
EXAMPLE: The incorporation of vessel pressure and subsequent stresses was tested on two problems: (1) a rectangular flume oriented at a $45^{\circ}$ angle to the $x$-axis and (2) through an application to Galveston Bay.

1. Angle flume. The first test case is a rectangular flume with dimensions of $1000 \mathrm{~m}$ in length, $50 \mathrm{~m}$ in width, and $1 \mathrm{~m}$ in depth (Figure 2). The vessel has a draft of $0.19 \mathrm{~m}$ and other properties as illustrated in Figure 3. These vessel properties are defined in section "Boundary File Implementation." The vessel is moving through the flume at $0.25 \mathrm{~m} / \mathrm{sec}$ from the lower-left to the upper-right portion of the flume.

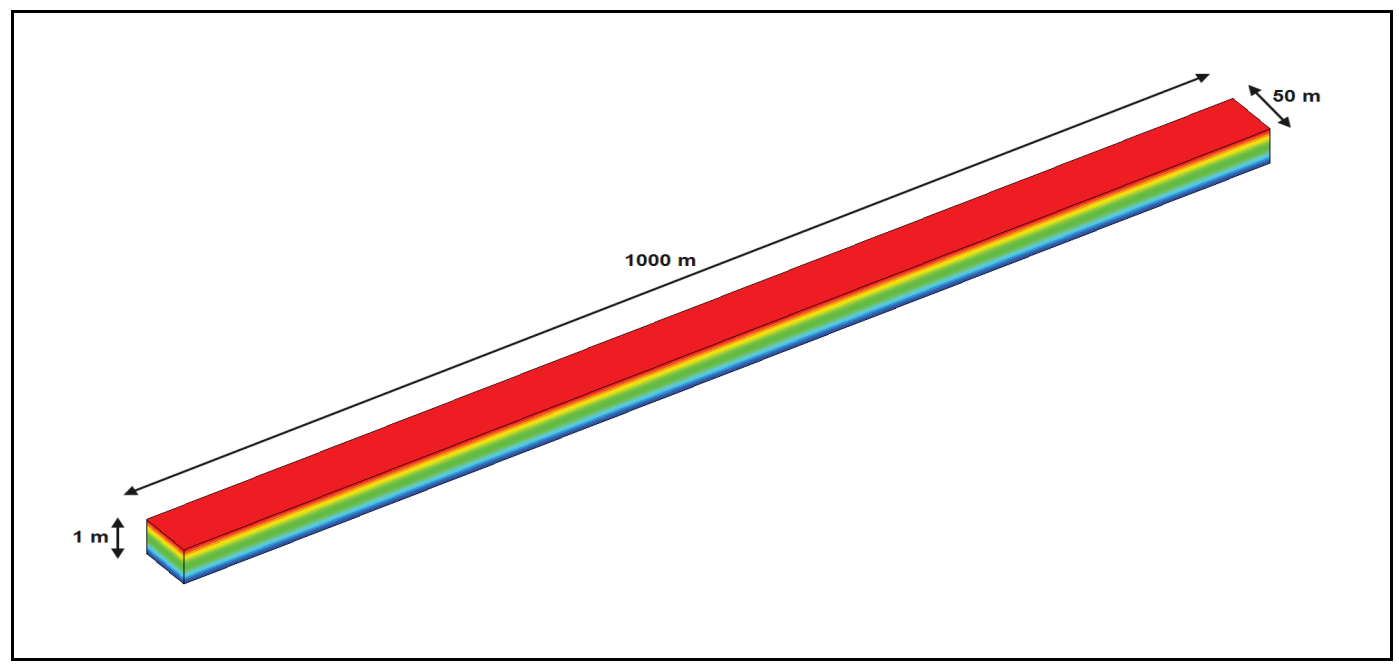

Figure 2. Angle flume domain.

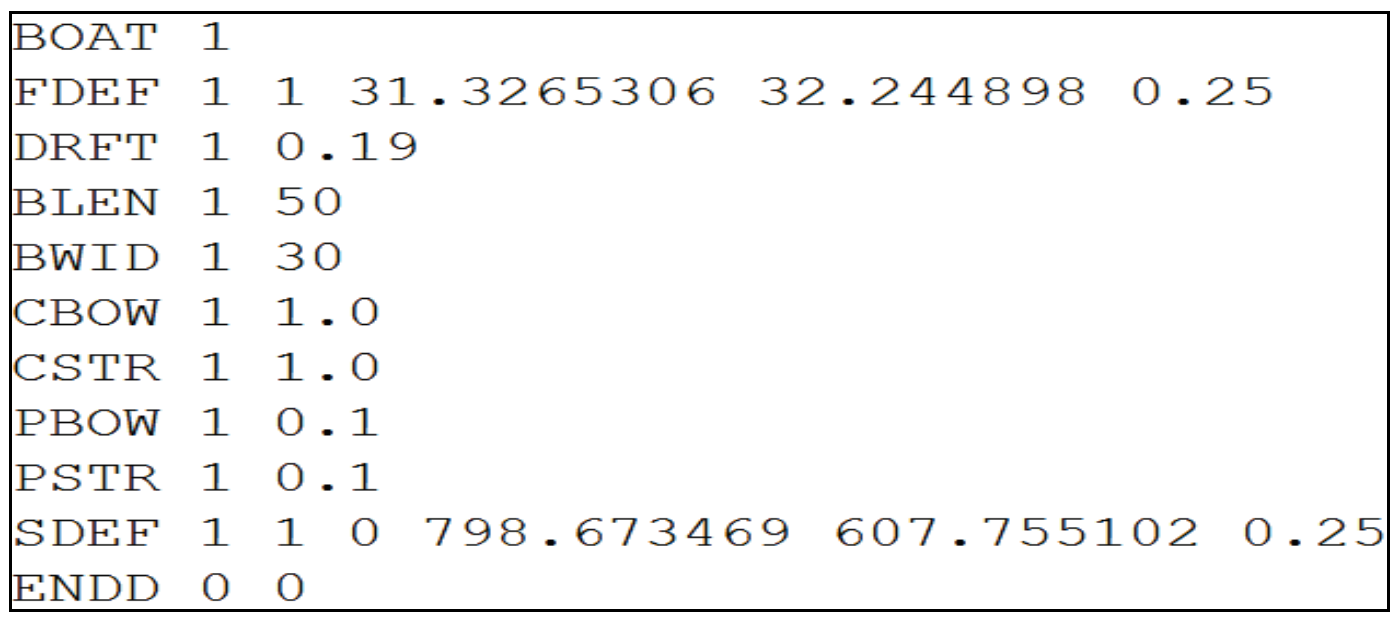

Figure 3. Boat definition parameters (parameters are defined in section "Boundary File Implementation").

Figure 4 illustrates the vessel-imposed surface pressure field. The bottom pressure under the vessel footprint should be $1.19 \mathrm{~m}$ because of the additional $0.19 \mathrm{~m}$ pressure imposed by the vessel. Figure 5 illustrates the bottom pressure under the vessel footprint and shows that the model correctly computes a pressure of $1.19 \mathrm{~m}$. 


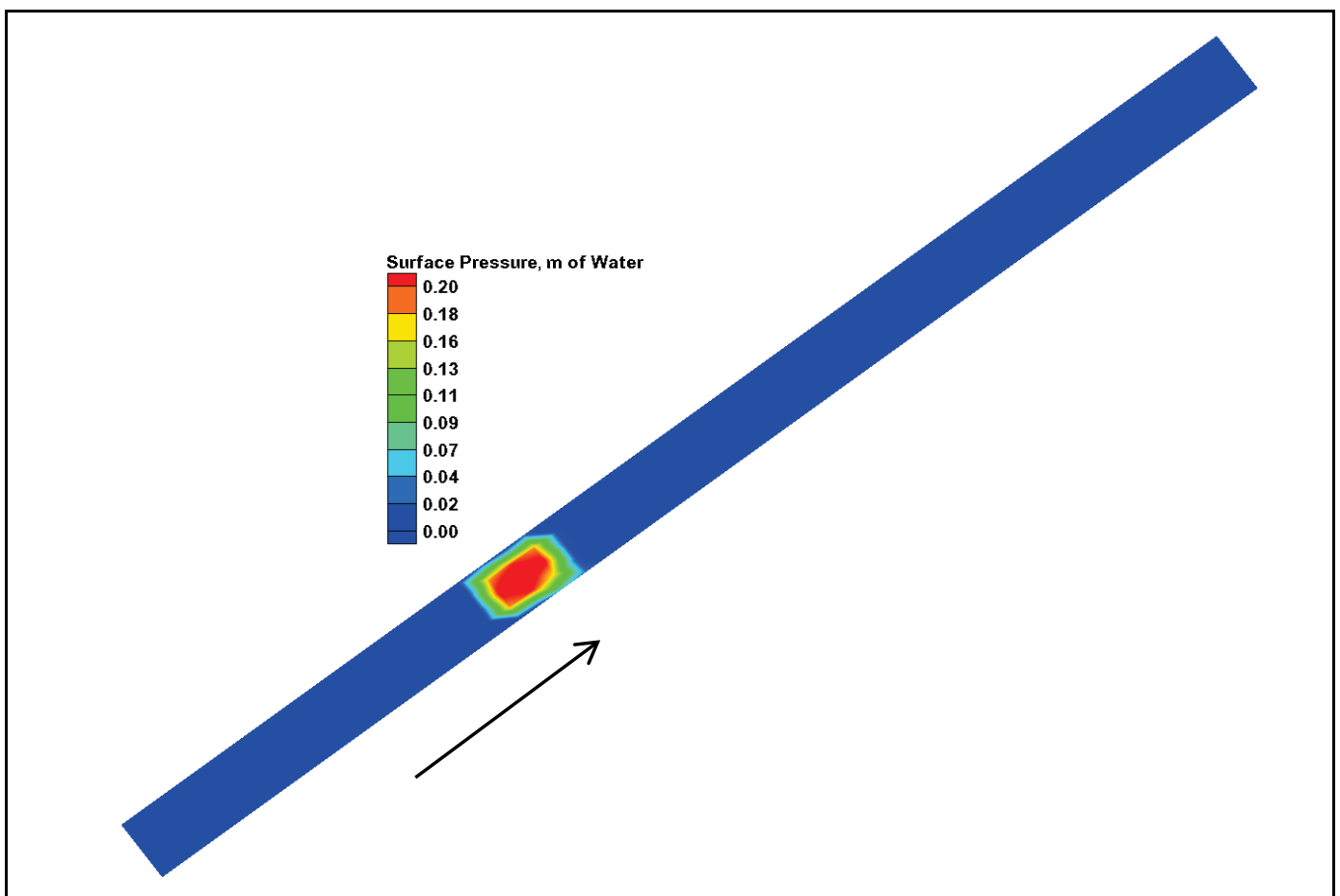

Figure 4. Vessel pressure imposed on the surface.

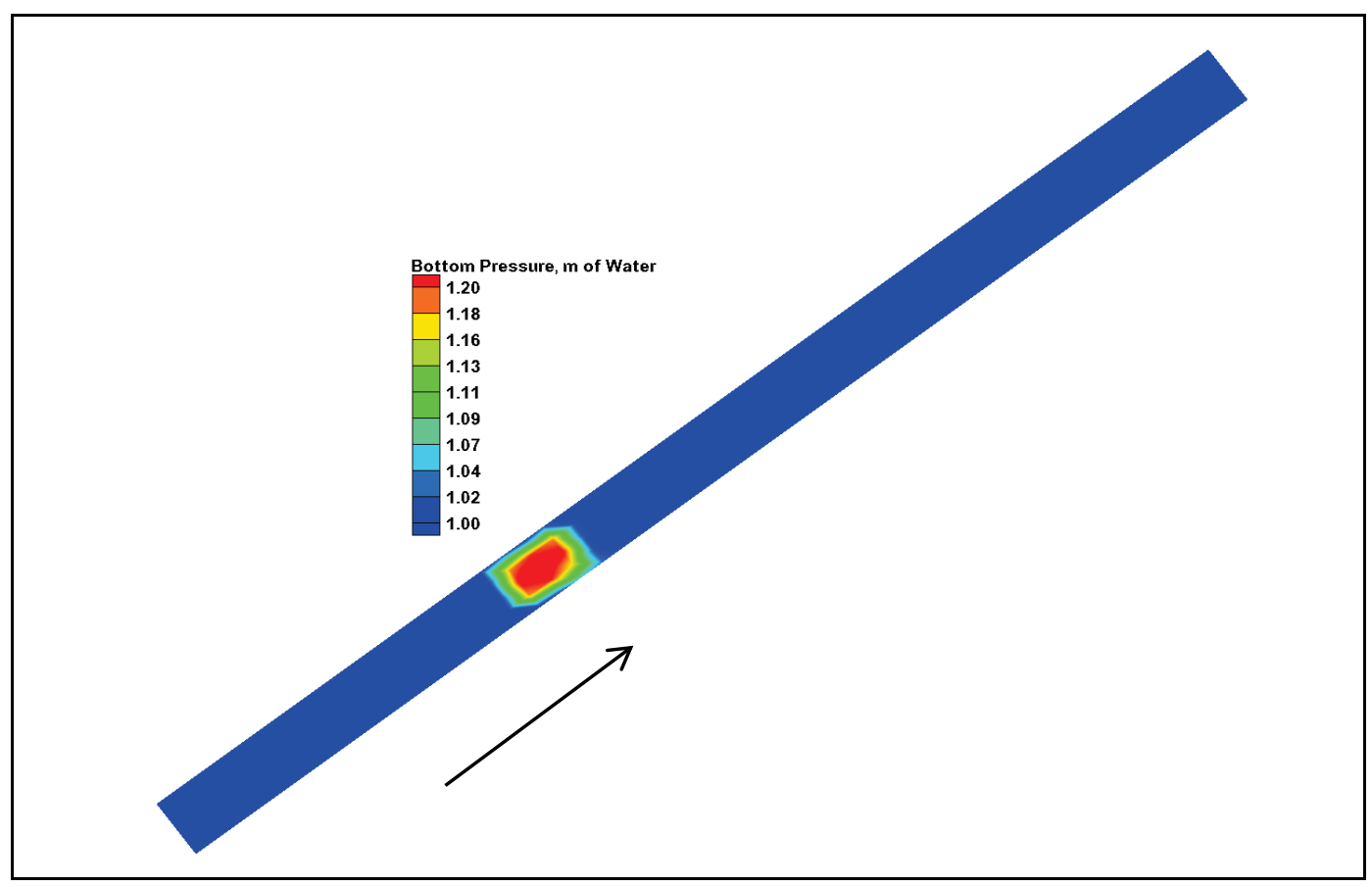

Figure 5. Vessel pressure imposed on the bottom.

Figures 6 and 7 illustrate the effects of the additional pressure imposed by the vessel on the velocities under and around the vessel. It is seen that the pressure field causes a velocity response on the bed, and this imparts an additional stress on the bed. 


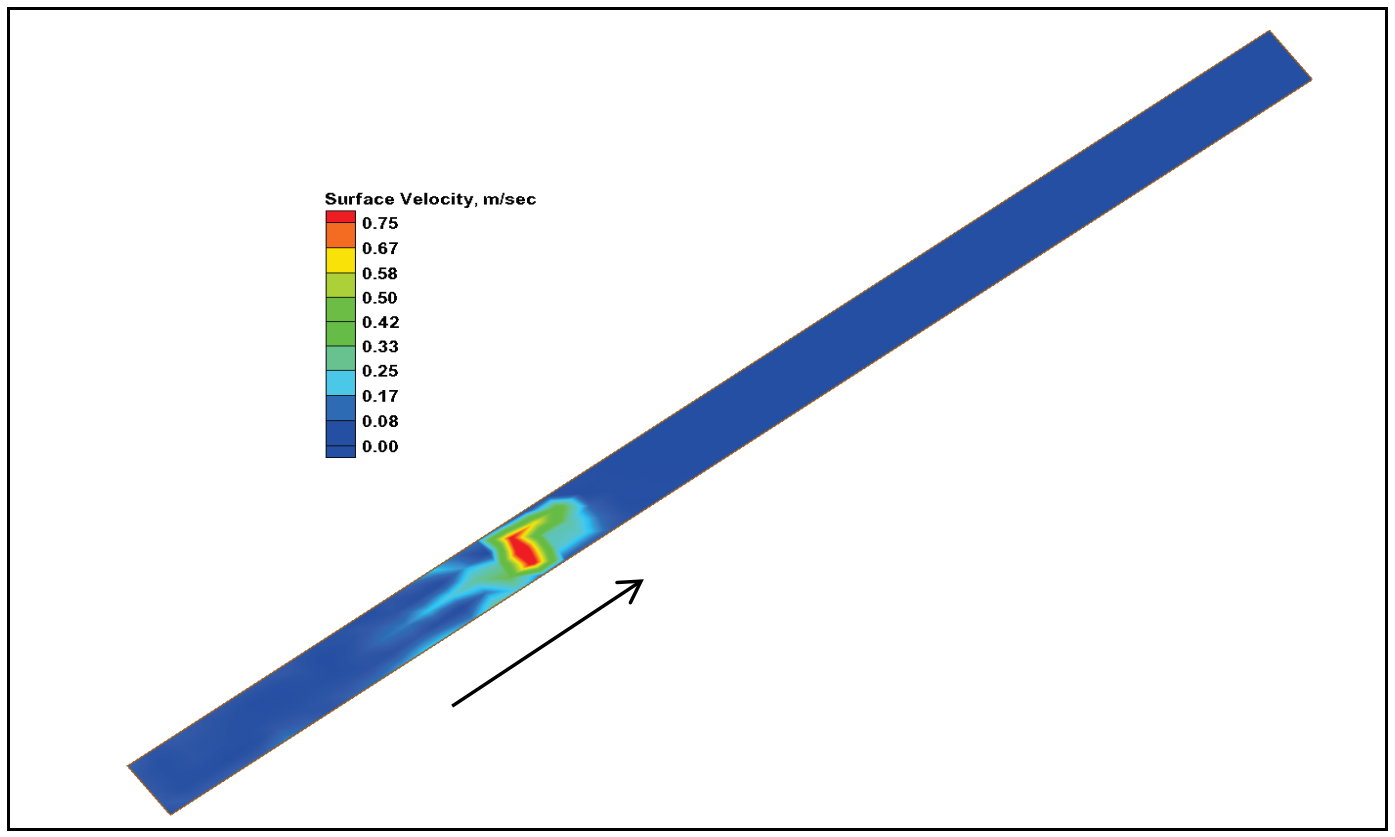

Figure 6. Surface velocity response to vessel pressure.

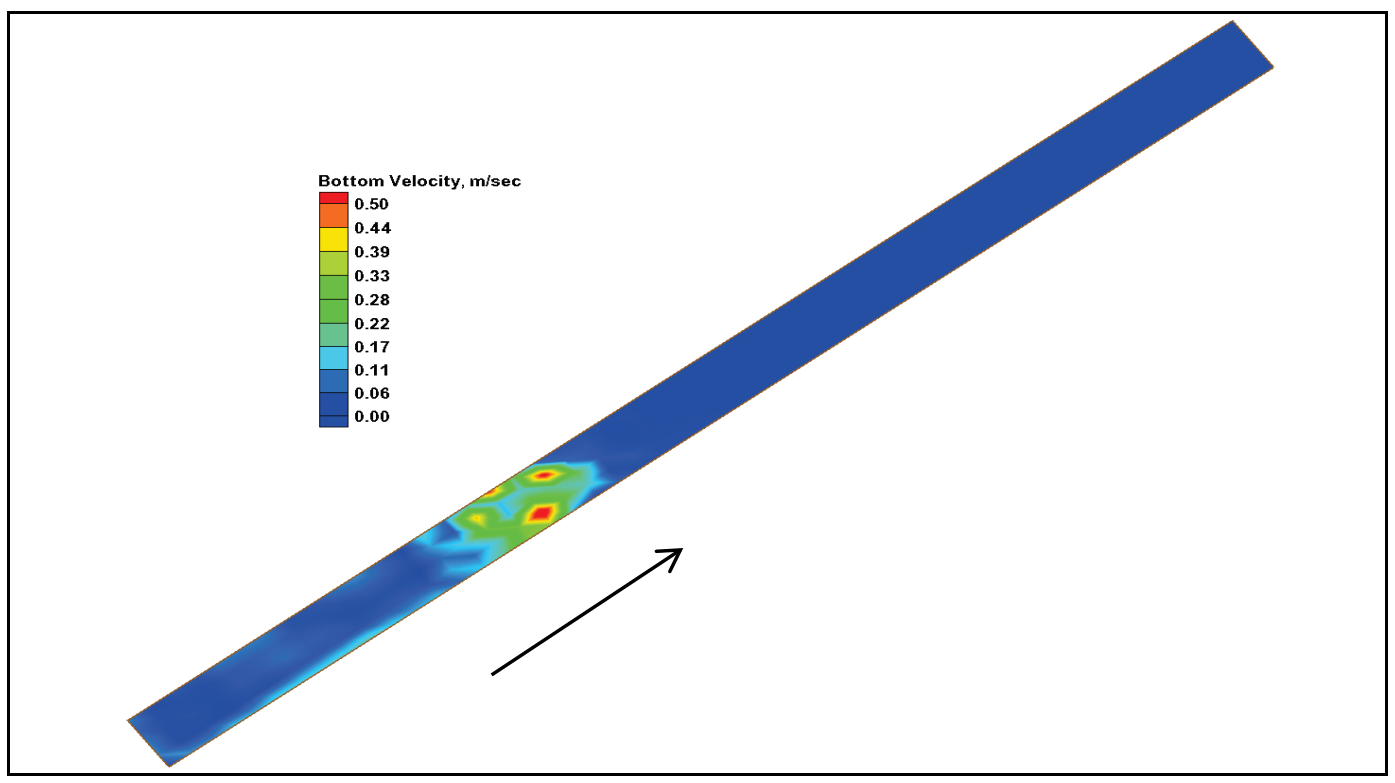

Figure 7. Bottom velocity response to vessel pressure.

2. Galveston Bay. The demonstration of boat pressure implementation was performed on a Galveston Bay example (Figure 8). This demonstration was comprised of a single vessel drafting $1 \mathrm{~m}$ traversing the Houston-Galveston ship channel in a channel of approximately $13 \mathrm{~m}$ depth, with vessel properties shown in Figure 9. These vessel properties are defined in section "Boundary File Implementation." This example was run with no tide, wind, inflow, or other forcings other than the moving vessel. Figures 10, 11, and 12 illustrate the vessel pressure field, the surface velocity, and the bottom velocity, respectively. The vessel is moving at $0.5 \mathrm{~m} / \mathrm{sec}$ into Galveston Bay, from lower right to upper left of the figures. 


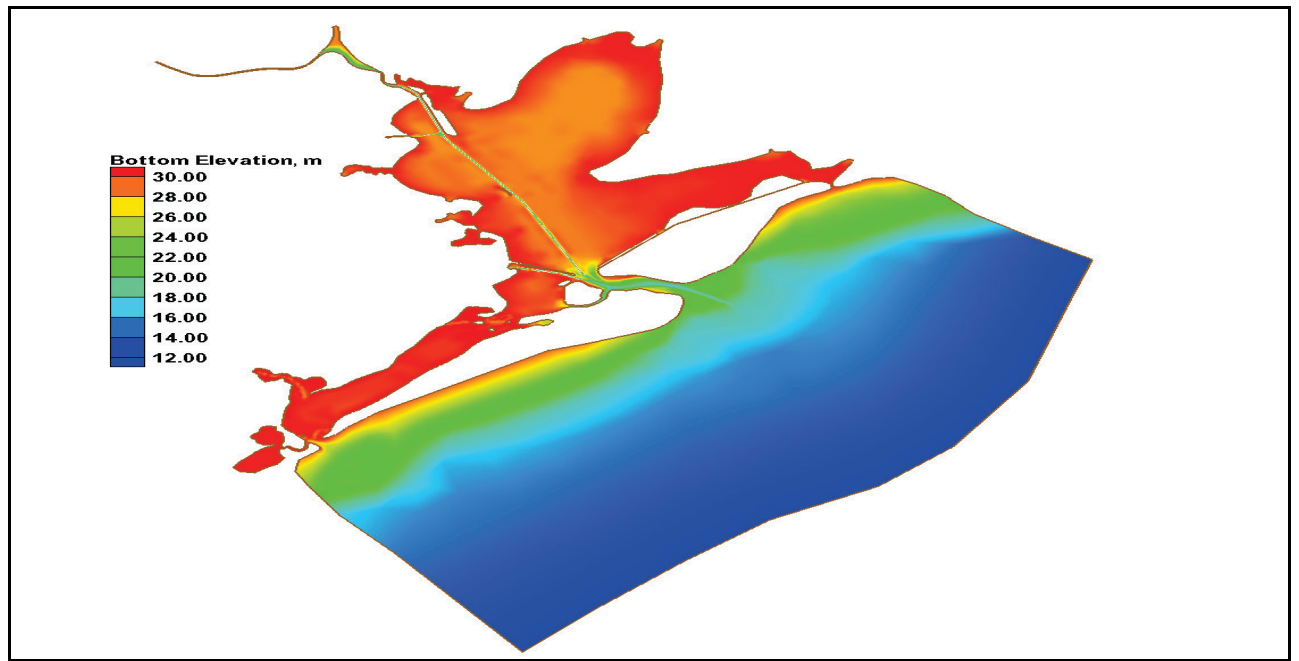

Figure 8. Galveston Bay ADH-SW3 domain.

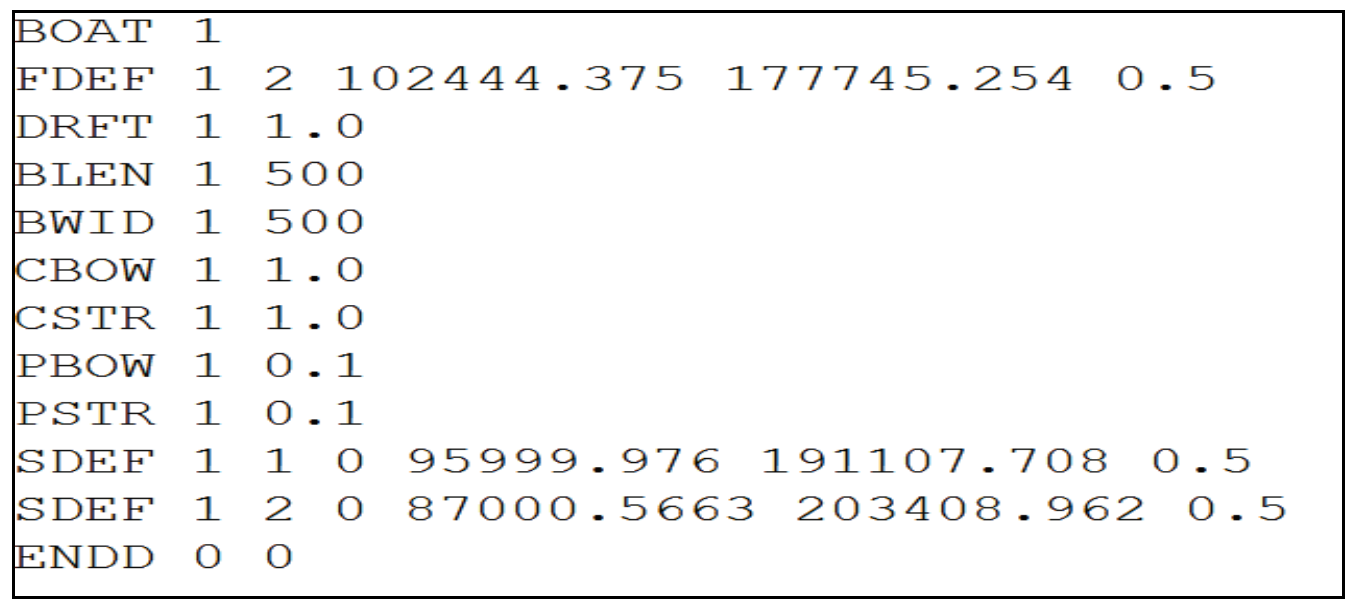

Figure 9. Boat definition parameters for Galveston Bay vessel (parameters are defined section "Boundary File Implementation.")

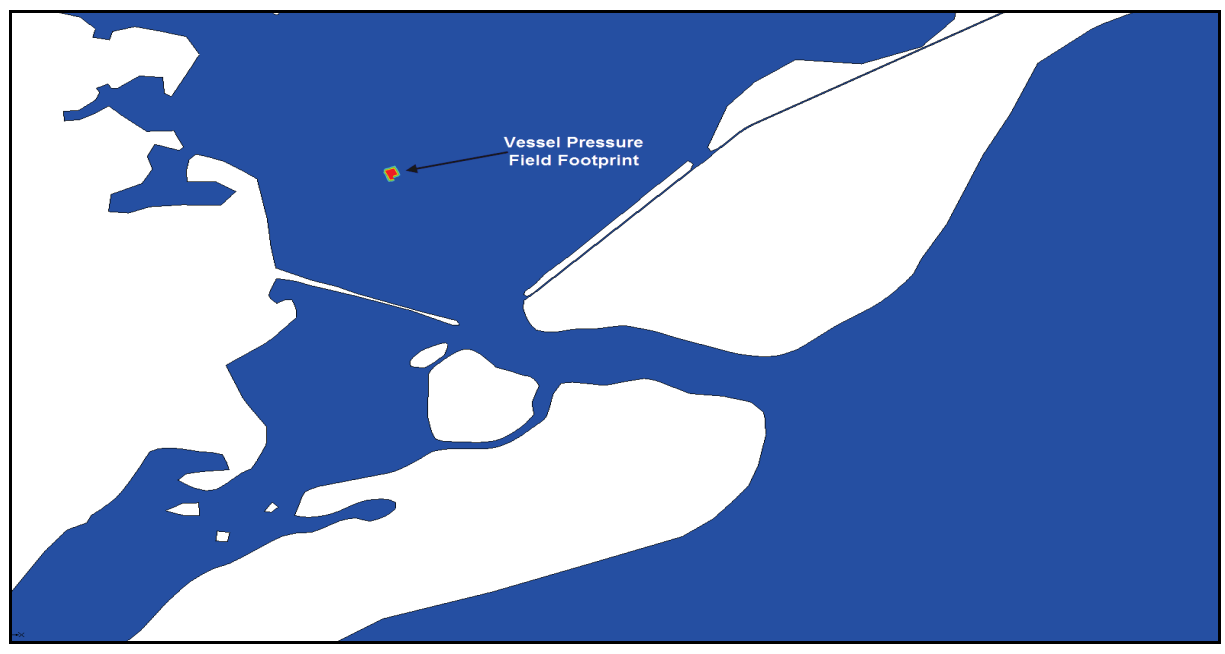

Figure 10. Vessel pressure footprint. 


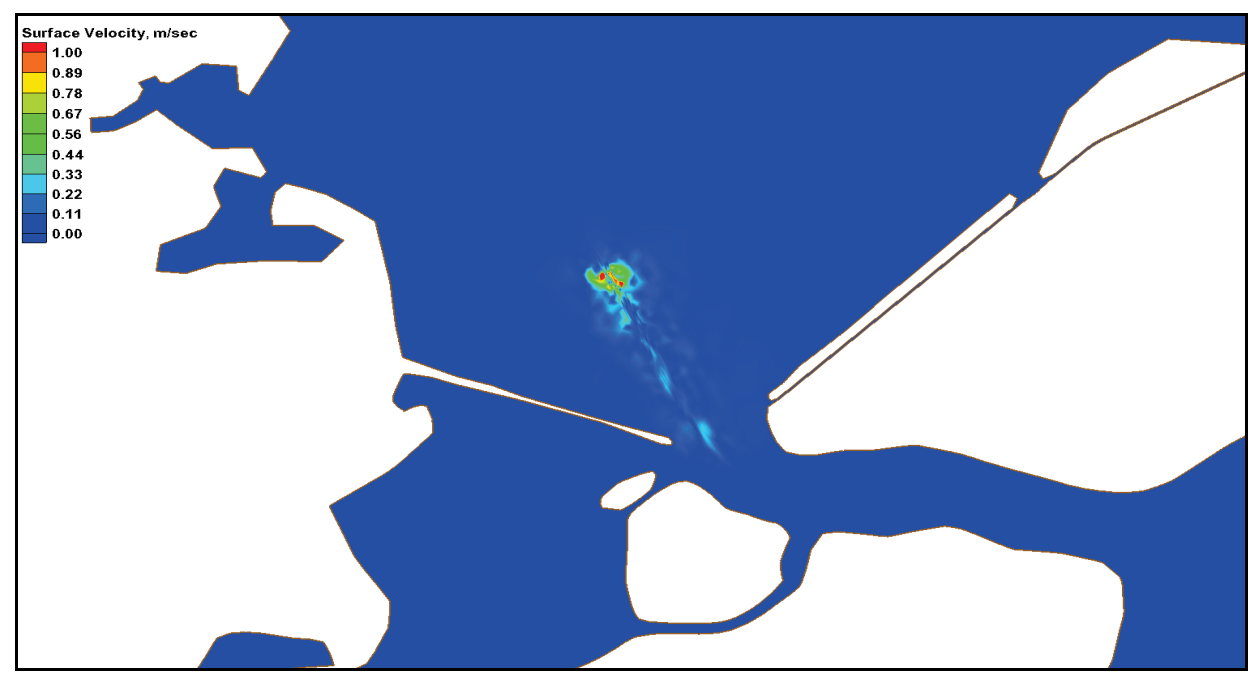

Figure 11. Surface velocity impact of vessel pressure.

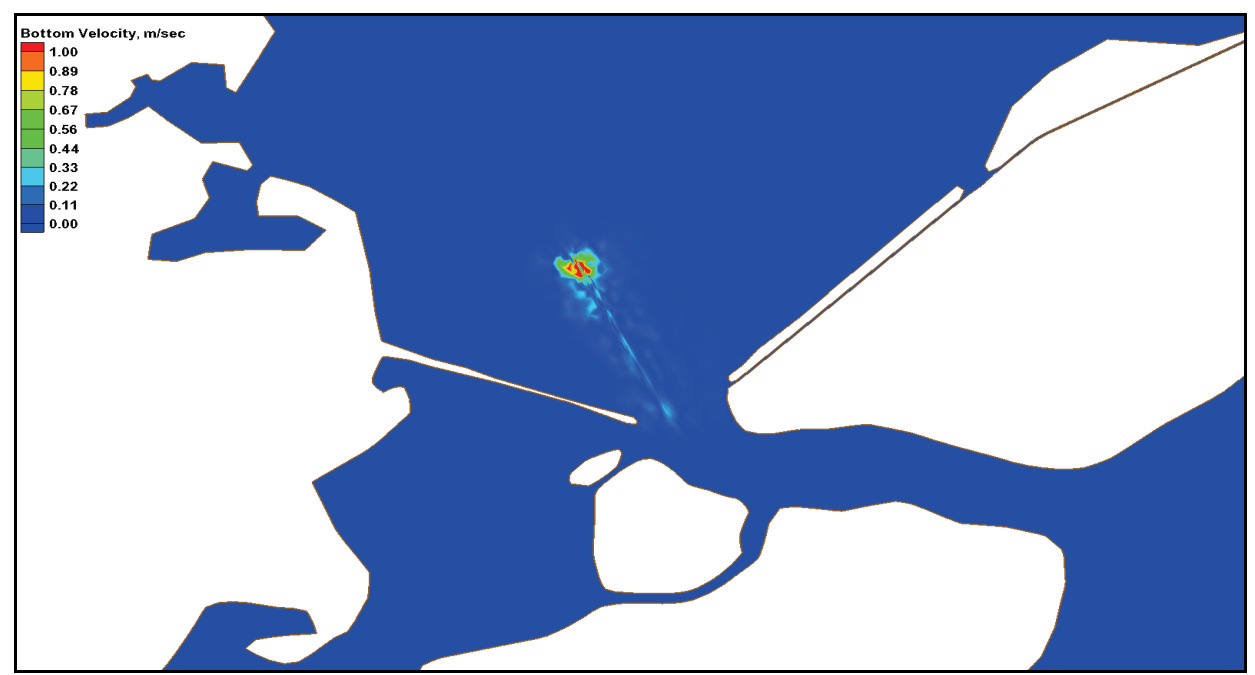

Figure 12. Bottom velocity impact of vessel pressure.

BOUNDARY FILE IMPLEMENTATION: The boat pressure field is activated in ADH-SW3 by the inclusion of the "OP BT" operation parameter card in the ADH-SW3 boundary conditions file (*.bc). In addition, a boat definition file (*.bt) must be specified. Presence of the OP BT card in the boundary conditions file and the absence of a boat definitions file will cause pre_adh to exit with an error.

The boat definitions files have a series of cards that define the vessel characteristics such as draft, length, etc. The first line in this file indicates how many vessels are being simulated. The card descriptions are as follows: 
Boat Definitions Control Cards

\section{BOAT}

\begin{tabular}{llll}
\hline Field & Type & Value & Description \\
1 & char & BOAT & Card type \\
2 & int & $>0$ & Number of vessels included
\end{tabular}

\section{FDEF}

\begin{tabular}{llll}
\hline Field & Type & Value & $\begin{array}{l}\text { SAILING LINE AND INITIAL VESSEL POSITION } \\
\text { Description } \\
1\end{array}$ \\
char & FDEF & Card type \\
2 & int & $>0$ & Vessel number \\
3 & int & $>0$ & Number of segments in vessel path \\
4 & real & $\#$ & x-coordinate of vessel's initial position \\
5 & real & $\#$ & y-coordinate of vessel's initial position \\
6 & real & $\#$ & Vessel velocity at initial position \\
DRFT & & & \\
\hline
\end{tabular}

\begin{tabular}{llll}
\hline Field & Type & Value & Description \\
1 & char & DRFT & Card type \\
2 & int & $>0$ & Vessel number \\
3 & real & $\#$ & Vessel draft, units of length
\end{tabular}

\section{BLEN}

\begin{tabular}{llll}
\hline & & & \\
Field & Type & Value & Description \\
1 & char & BLEN & Card type \\
2 & int & $>0$ & Vessel number \\
3 & real & $\#$ & Vessel length, units of length
\end{tabular}

\section{BWID}

\begin{tabular}{llll}
\hline Field & Type & Value & Description \\
1 & char & BWID & Card type \\
2 & int & $>0$ & Vessel number \\
3 & real & $\#$ & Vessel width, units of length \\
PBOW & & & \\
\hline
\end{tabular}

\begin{tabular}{llll}
\hline Field & Type & Value & Description \\
1 & char & PBOW & Card type \\
2 & int & $>0$ & Vessel number
\end{tabular}


PSTR

\begin{tabular}{|c|c|c|c|}
\hline & & & STREN TO LENGTH RATIO \\
\hline Field & Type & Value & Description \\
\hline 1 & char & PSTR & Card type \\
\hline 2 & int & $>0$ & Vessel number \\
\hline 3 & real & \# & Ratio of vessel stern length to vessel length \\
\hline \multicolumn{4}{|c|}{ CBOW } \\
\hline & & & FRACTION OF DRAFT APPLIED TO PBOW \\
\hline Field & Type & Value & Description \\
\hline 1 & char & CBOW & Card type \\
\hline 2 & int & $>0$ & Vessel number \\
\hline 3 & real & \# & Ratio of vessel bow to vessel draft \\
\hline
\end{tabular}

\begin{tabular}{llll}
\hline Field & Type & Value & \multicolumn{1}{c}{ FRACTION OF DRAFT APP } \\
1 & char & CSTR & Card type \\
2 & int & $>0$ & Vessel number \\
3 & real & $\#$ & Ratio of vessel stern to vessel draft
\end{tabular}

PROP

\begin{tabular}{llll}
\hline Field & Type & Value & Pescription \\
1 & char & PROP & Card type \\
2 & int & $>0$ & Vessel number \\
3 & int & 1 or 2 & Propeller type \\
4 & real & $>0$ & Propeller diameter \\
5 & real & $>0$ & Distance between centers of propellers \\
6 & real & $>0$ & Tow vessel length \\
7 & real & $>0$ & Distance from props to stern of tow vessel
\end{tabular}

SDEF

\begin{tabular}{llll}
\hline Field & Type & Value & \multicolumn{1}{c}{ SAILING LINE SEGMENT DEFINITION } \\
1 & char & SDEF & Card type \\
2 & int & $>0$ & Vessel number \\
3 & int & $>0$ & Sailing line segment number \\
4 & int & 0 or 1 & Type of segment $(0=$ line; $1=$ arc $)$ \\
5 & real & $\#$ & x-coordinate of segment end \\
6 & real & $\#$ & y-coordinate of segment end \\
7 & real & $\#$ & Vessel velocity at segment end
\end{tabular}




$\begin{array}{llll}8 & \text { real } & \# & \text { X-coordinate of arc center } \\ 9 & \text { real } & \# & \text { y-coordinate of arc center } \\ 10 & \text { real } & +1 /-1 & \text { Direction of arc turn ( }+1 \text { for left, }-1 \text { for right })\end{array}$

\section{ENDD}

$\begin{array}{llll}\text { Field } & \text { Type } & \text { Value } & \text { Description } \\ 1 & \text { char } & \text { ENDD 0 0 } & \text { Card type }\end{array}$

SUMMARY AND CONCLUSIONS: This CHETN describes the development and testing of the capability to simulate vessel-generated currents and stresses into ADH-SW3. Two examples are provided demonstrating this capability, and these examples demonstrate that the ADH-SW3 code is accurately simulating the resultant pressures and currents. This implementation of vesselgenerated currents and stresses ignores the vertical accelerations; therefore, velocities near the vessel are not accurate and should not be used for the design of engineered channels without careful engineering judgment. The "Boundary Condition File Implementation" section also provides all the information necessary for a user to include and activate this capability in ADHSW3.

POINTS OF CONTACT: This CHETN was prepared as part of the Flood and Coastal (F\&C) Damage Reduction program of the U.S. Army Corps of Engineers. The POC for technical inquiries is Jennifer N. Tate (Jennifer.N.Tate@USACE.Army.mil). For information about the F\&C program, please contact the F\&C Program Manager, Cary A. Talbot (Cary.A.Talbot@usace.army.mil).This technical note should be referenced as follows:

Savant, G., and C. J. Trahan. 2015. Shallow Water Adaptive Hydraulics (ADHSW3): Waterborne vessels. ERDC/CHL CHETN-IV-106. Vicksburg, MS: U.S. Army Engineer Research and Development Center.

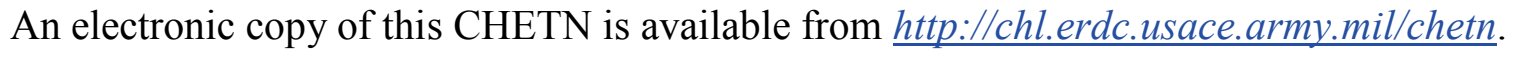

\section{REFERENCES}

Maynord, S. T. 1996. Return velocity and drawdown in navigable waterways. Technical Report HL-96-7. Vicksburg, MS: U.S. Army Corps of Engineers Waterways Experiment Station.

Stockstill, R. L., and R. C. Berger. 1999. A two-dimensional flow model for vessel-generated currents. Technical Report ENV Report 10. Vicksburg, MS: U.S. Army Corps of Engineers Waterways Experiment Station.

NOTE: The contents of this technical note are not to be used for advertising, publication, or promotional purposes. Citation of trade names does not constitute an official endorsement or approval of the use of such products. 